\title{
INCLUSÃO DE PESSOAS COM DEFICIÊNCIA NO MERCADO DE TRABALHO: A RELEVÂNCIA DAS ATIVIDADES MERCADOLÓGICAS E SOCIAIS
}

\author{
INCLUSION OF PEOPLE WITH DISABILITIES IN THE LABOUR MARKET: THE \\ RELEVANCE OF MARKET AND SOCIAL ACTIVITIES
}

\section{Lucas Esteves Fernandes}

Graduado em Administração pela Alfa Unipac, Aimorés/MG, Brasil

E-mail: lucasesteves96@hotmail.com

Charleston Sperandio de souza Mestre e Professor de Administração pela Alfa Unipac, Aimorés/MG, Brasil E-mail: charleston.sperandio@yahoo.com.br

\section{Resumo}

O presente artigo teve como objetivo analisar e compreender as dificuldades da inclusão da Pessoa com Deficiência (PcD) no mercado de trabalho, partindo de pesquisas bibliográficas, trazendo definições sobre o termo deficiência, que pode ser física, intelectual, visual, auditiva ou múltipla, que nasce com a pessoa ou não, podendo ser definitiva ou temporária. Além disso, discorreu sobre os pressupostos legais que fundamentam a inclusão da $\mathrm{PcD}$ no mercado de trabalho, em que são grandes as barreiras encontradas por essas pessoas, seja por desconhecimento do que the é de direito, da falta de capacitação, seja pelo não cumprimento do que estabelece as bases legais por parte das empresas, sendo obrigatória uma lei de cotas para possibilitar a inclusão dessa população no mercado de trabalho, ou ainda pela falta de interesse e de informação dos empresários. Conclui-se que a inclusão da PcD no mercado de trabalho é um assunto que ainda deve ser bastante abordado, e que as falhas nesse processo são nítidas, necessitando estabelecer uma relação de parceria e cooperação entre empresas, sociedade e governo afim de garantir que essas pessoas exerçam uma atividade econômica.

Palavras-Chave: Mercado de trabalho; pessoa com deficiência; lei de cotas.

\begin{abstract}
This article aimed to analyze and understand the difficulties of including People with Disabilities $(\mathrm{PwD})$ in the job market, starting from bibliographic research, bringing definitions about the term disability, which can be physical, intellectual, visual, hearing or multiple, that is born with the person or not, being able to be definitive or temporary. In addition, he spoke about the legal assumptions that underlie the inclusion of PwD in the labor market, in which the barriers encountered by these
\end{abstract}


people are great, either due to lack of knowledge of what is their right, lack of training, or non-compliance with the which establishes the legal bases for companies, and a quota law is mandatory to enable the inclusion of this population in the labor market, or even due to the lack of interest and information of entrepreneurs. It is concluded that the inclusion of PwD in the labor market is a subject that still needs to be addressed, and that the flaws in this process are clear, needing to establish a partnership and cooperation relationship between companies, society and government in order to ensure that these engage in economic activity.

Keywords: Labor market; person with disabilities; quota law

\section{Introdução}

A inclusão de pessoas com deficiência no mercado de trabalho envolve um grande desafio dentro das empresas. Apesar de ser um assunto transitado na sociedade há alguns anos, a partir do surgimento da reflexão acerca dos limites de responsabilidade social das organizações, verifica-se uma grande dificuldade para que as empresas de fato cumpram com as suas obrigações perante a lei.

As pessoas com deficiência representam cerca de 6,7\% da população brasileira, em que as mesmas buscam oportunidades para incluir-se de maneira sólida na sociedade, o que implica acesso imparcial ao direito de ir e vir, de desenvolver uma vida social ativa e de ter acesso ao trabalho conforme previsto em lei (IBGE, 2010).

Segundo Willians (2000), o mercado de trabalho é justamente o campo em que há a maior lacuna entre as pessoas com e sem deficiência.

Fundamentado na Pesquisa Nacional por Amostra de Domicílios Contínua (Pnad Contínua), a porcentagem de inativos entre as pessoas sem deficiência era de $31 \%$ no segundo trimestre do ano de 2019, enquanto entre pessoas com deficiência esse valor correspondia cerca de 63\%.

Várias empresas acreditam e valorizam a inclusão e a diversidade e tomam iniciativas concretas; porém, é também possível perceber casos de empresas que nem sequer cumprem os requisitos mínimos exigidos pela Lei de Cotas. A Relação Anual de Informações Sociais (RAIS) de 2017 mostra esse cenário: apenas 0,70\% do total de vagas do mercado formal é preenchido por pessoas com deficiência (Ministério do Trabalho e Emprego, 2018). 
Assim, como informam Ribeiro e Carneiro (2009), a existência de norma jurídica, individualmente, não é suficiente para assegurar-lhes oportunidades efetivas no mercado de trabalho, de maneira que eles possam exercer suas atividades com todo respaldo e estrutura que lhes são de direito.

Nessa linha, o estudo se justifica na obtenção de dados por meio de pesquisa bibliográfica, e observar a adequação das condições e práticas de trabalho por parte das empresas, sendo o mesmo importante para destacar a realidade constante dos problemas e dificuldades enfrentadas pelas Pessoas com Deficiência para garantirem seu espaço no mercado de trabalho perante os aspectos legais.

De acordo com esse contexto, a presente pesquisa tem como objetivo conhecer os desafios e superações no ambiente de trabalho da pessoa com deficiência, e sobre os direitos para sua inserção no mercado.

Assim, torna-se imperativo que a sociedade como um todo tenha conhecimento sobre as questões que englobam a Pessoa com Deficiência, tomando consciência e atitudes efetivas para melhorarem os índices de aceitação dessas pessoas no mercado.

\subsection{O Mercado de Trabalho e os Portadores de Deficiências}

O mercado de trabalho é uma denominação utilizada para se referir as formas de trabalho que possam existir, sendo remunerados de alguma forma, seja trabalho manual ou intelectual. As pessoas vendem sua força de trabalho por uma remuneração ou salário, que pode ser em dinheiro, moradia, bonificação, ou outra forma de pagamento pelo trabalho exercido. Essas relações são desenvolvidas pelo processo do meio que estão inseridas, como por exemplo, mudanças tecnológicas, mercado globalizado e as modificações no cenário econômico, social, cultural e demográfico (DUTRA, 2011).

Seguindo o mesmo contexto, Daft (2005) explica que esses argumentos permitem afirmar que as relações são complexas entre as pessoas e as organizações; e que se ambas não se prepararem perderão vantagens competitivas no mercado, em que as organizações de hoje precisam se adaptar às novas situações se quiser sobreviver e prosperar. Desta forma as organizações estão se 
tornando cada vez mais enigmáticas, necessitando de pessoas cada vez mais preparadas e capacitadas para atender os crescentes níveis de complexidade existentes atualmente.

Considera-se portador de deficiência e necessidades especiais a pessoa que apresenta em caráter definitivo ou temporário, significativas diferenças intelectuais, sensoriais ou físicas, decorrentes de fatores inatos ou adquiridos que resulte na dificuldadede interação social e profissional necessitando, assim, de auxílio para desenvolver seu potencial e minimizar as dificuldades (BECHTOLD; WEISS, 2005).

De acordo com Instituto Ethos de Empresas e Responsabilidade Social (2002), a caracterização de pessoas com deficiência depende de vários conceitos: as deficiências podem ser físicas, intelectuais ou sensoriais, de caráter nato ou uma aquisição ao longo da vida por algum acidente ocorrido ou doença desenvolvida.

Pastore (2000, p.34) defende que

a ciência nas organizações tenha como fundamento a inibição de práticas discriminatórias e que criem condições para que se veja a presença dos profissionais com deficiência com desejo e apreço, em detrimento daquelas que posicionam em seu interior a simples busca pelo seu aspecto legal.

Observa-se neste cenário que, "as empresas consideradas competentes e com visão de futuro [...] entendem a diversidade como forma de agregar valores e diferenciar seus produtos" (PASTORE, 2000, p.36).

Schwarz e Haber (2009) aprofundam sobre o assunto, afirmando que a empresa adquire um diferencial competitivo, já que em mercados globalizados, é fundamental saber lidar com as diferenças para se alcançar o sucesso desejado e Bohlander (2009, p.62) contribui para a discussão resgatando o conceito de gestão da diversidade, que "vem fornecendo, às organizações, práticas que visem garantir resultados à organização e às pessoas que nela trabalham, com ambientes mais benéficos à produtividade, bem-estar e qualidade de trabalho", afirmando que as empresas, ao praticarem a integração, a inclusão e a diversidade, são bem vistas aos olhos da sociedade.

Em relação à visão mercadológica, a empresa pode obter capital reputacional, seja objetivamente pela imagem que o consumidor passa a ter da empresa, como eticamente constituída - informação destacada por meio de pesquisa do Instituto Ethos sobre a percepção do consumidor brasileiro, a qual apontou que $43 \%$ dos 
consumidores afirmaram que a contratação de pessoas com deficiência está em primeiro lugar entre os fatores que os estimulariam a comprar mais produtos de uma empresa por gerar uma mudança de modelo mental mostrando a relevância da inclusão da Pessoa com Deficiência no contexto das atividades mercadológicas e sociais (INSTITUTO ETHOS, 2002).

De acordo com o extinto Ministério do Trabalho e Emprego, vem sendo desenvolvidas diversas políticas para que haja igualdade de oportunidades de emprego para os grupos socialmente mais desfavorecidos da população, principalmente a Pessoa com Deficiência, garantindo tratamento dos indivíduos, em todos os aspectos relacionados ao emprego - contratação, promoção, treinamento etc. - de uma forma justa e não tendenciosa.

\subsection{A Lei de Cotas de 1991}

A lei de cotas foi criada em 1991 com o intuito, conforme o extinto Ministério do Trabalho e Emprego, de incluir as pessoas com deficiência no mercado de trabalho e consequentemente na sociedade, oferecendo a elas iguais condições aos demais trabalhadores, fazendo jus ao Artigo $5^{\circ}$ da Constituição Federal de 1988 que trata, sobretudo da igualdade de todos perante a lei.

A citada lei é uma forma de oferecer oportunidades para pessoas com algum tipo de deficiência, fazendo com que as empresas busquem respeitar os princípios constitucionais dos valores sociais do trabalho e da livre iniciativa, para que se torne possível à execução da cidadania plena e a integridade do trabalhador com ou sem deficiência (art. 1ํe 170 da CF/88).

De acordo com o site Fundação Dorina Nowill, a Lei de Cotas 8.213/91 trata sobre os Planos da Previdência e outras determinações sobre a contratação de pessoas com deficiência.

O Art. 93 determina que todas as empresas com mais 100 ou mais funcionários está obrigada a preencher de dois a cinco por cento dos seus cargos com beneficiários reabilitados, ou PcD (Pessoas com Deficiência) na proporção apresentada na tabela 1 a seguir. 
Tabela 1: Porcentagem de contratação de PcD conforme quadro de funcionários.

\begin{tabular}{c|c}
\hline Até 200 funcionários & $2 \%$ de PcD \\
\hline De 201 a 500 funcionários & $3 \%$ de PcD \\
\hline De 501 a 1.000 funcionários & $4 \%$ de PcD \\
\hline De 1.001 funcionários em diante & $5 \%$ de PcD \\
\hline
\end{tabular}

Fonte: Lei de Cotas 8.213/91 - Art. 99

Nota: Tabela realizada pelos autores.

Lancelotti (2001) pressupõe que a dificuldade de inserção da pessoa com deficiência no mercado de trabalho se dá devido à inadequação dos processos de formação, ao preconceito social e o desconhecimento da capacidade dessas pessoas, não devendo menosprezar a aptidão física e mental desse grupo.

Stainback e Stainback (1999, p.96) afirmam que "a inclusão de tais pessoas é uma atitude, [...], e não uma ação ou um conjunto delas. É um modo de vida, fundado na convicção de que cada indivíduo é estimado e pertence a um grupo", e completam, é uma dificuldade que deve ser constantemente trabalhada é a falta de experiência das pessoas que fazem parte de determinada empresa em conviver com pessoas portadoras de deficiência.

Em análise realizada pelo Instituto Ethos (2002) aponta que para essa questão várias empresas especializadas em contratação e recolocação têm desenvolvido um tipo de trabalho denominado "sensibilização de funcionários" que procura criar a integração por meio de mini cursos, relatos de pessoas com deficiência empregadas e pessoas que conviveram com pessoas com deficiência no ambiente de trabalho e tenham experiências positivas.

Essas ações devem ser idealizadas com a participação dos dirigentes das empresas de modo que se desperte o respeito às diferenças e responsabilidade social. Por outro lado, o espírito de equipe desenvolvido nesse tipo de ação consegue envolver coletivamente a empresa na busca pela inclusão, trazendo, consequentemente, resultados positivos aos olhos da sociedade. 
Até mesmo nos dias atuais, observa-se que o preconceito ainda é um dos grandes problemas da cultura humana, dificultando o processo de inclusão e aceitação daquele que é, por algum motivo, diferente.

Por isso, o Instituto Ethos (2002) aponta duas formas muito simples de superar alguns atos de preconceito:

a) Utilizar termos e linguagens corretas para se referir à pessoa com deficiência, principalmente quanto à definição e esclarecimento do tipo de deficiência que possui, para não causar ressentimento e a

b) Sensação de inferioridade ao portador de deficiência.

Percebe-se que algumas mudanças de mentalidade que vem ocorrendo em meio às organizações: antes as empresas buscavam as pessoas com deficiência simplesmente para cumprir um requisito legal.

No entanto, ainda que de maneira contida, essa mentalidade vem sofrendo mudanças, mostrando que as organizações podem lidar com diferentes tipos de deficiência e adaptar cada pessoa em funções específicas.

Assim, na atualidade, as empresas precisam aprender a lidar com os diversos tipos de funcionários e as necessidades e interesses individuais de cada um. Com isso, muitas vezes é necessário repensar e reorganizar a forma como estão conduzindo suas organizações para que o funcionário possa se sentir satisfeito e trazer bons resultados e para que a empresa também fique satisfeita com ele, afirma Bohlander (2009).

\subsection{A Responsabilidade Social e a Deficiência}

O Instituto Ethos de Empresas e Responsabilidade Social (2002, p.1) afirma que "a deficiência já foi vista como um problema do próprio deficiente, de sua família e das entidades de assistência a essas pessoas, enquanto que a deficiência era vista como uma questão de saúde, ou seja, como se fosse uma doença”. Ainda no entendimento do Instituto, há uma expansão da ideia de que a inclusão de deficientes é uma questão de respeito, ética, cidadania e redução da desigualdade, e que essas pessoas também são capazes de exercer atividades que a elas são designadas. 
Observa-se que construir uma educação que abranja todos os segmentos da população depende de ações governamentais, e cada indivíduo com suas particularidades resulta em ações baseadas não na individualização, mas trabalhando a inclusão de todos de maneira correta e eficiente, aproveitando o que todas as pessoas têm de melhor para oferecer (MAZZOTA, 2005).

Adam Smith, em uma de suas primeiras abordagens sobre a responsabilidade social enfoca o bem-estar coletivo, partindo do indivíduo, dizendo que, ao perseguir os próprios interesses, o indivíduo promove os interesses da sociedade, de forma mais eficaz do que quando tem a intenção de realmente promovê-los (SMITH, 1983; apud BARBIERI; SIMANTOB, 2007).

Os autores Friedman (1970) e Tenório (2004) possuem visões complementares, no que diz à responsabilidade social. O primeiro afirma que, se a empresa gerar ganhos financeiros dentro da lei, está produzindo um bem ou serviço socialmente importante e pode remunerar os fatores de produção, gerando renda para a sociedade e o devido pagamento de impostos para o governo, que por sua vez, deve ser mais preparado para resolver os problemas sociais. Já o segundo autor possui uma visão voltada para o contexto econômico, que engloba gerar receita, criar os empregos, pagar os impostos e obter dividendos e cumprir as obrigações previstas em lei, fazendo nada mais o que the é de obrigação.

Ainda nos entendimentos dos autores Friedman (1970) e Tenório (2004), a inserção da responsabilidade social é definida com base no argumento de que o perfil das decisões e o tipo de ações adotadas pela organização, no âmbito da responsabilidade social, devem refletir o posicionamento ético e moral dos tomadores de decisões e os mesmos também defendem a adoção de políticas organizacionais com foco na responsabilidade social com o argumento de que a empresa se beneficiará como um todo, principalmente no longo prazo, pois passará a ser bem vista pela sociedade, cumprindo o seu papel de acolher uma classe menos priorizada no que se refere à obtenção de emprego. Por outra perspectiva, as questões de competitividade interferem no processo de inclusão de pessoas com deficiência no contexto organizacional.

Segundo Barbiere e Simantob (2007), o mercado cada vez mais competitivo faz com que as empresas aumentem as exigências técnicas sobre seus 
trabalhadores, busque redução de custos e maior eficiência financeira, o que acaba se tornando uma barreira na inclusão de pessoas com deficiência no ambiente organizacional.

Para Dutra (2011), as organizações, em especial seus gerentes, podem encontrar satisfação por meio de criação de valor social. Um número cada vez maior de empresas está reconhecendo as possibilidades de criar e buscar trajetórias paralelas e complementares à sua atividade principal em busca dos lucros convencionais, mas, principalmente, pela criação de valor social para a organização, que tem se tornado algo cada vez mais importante para a expansão de qualquer empresa em seu mercado de atuação.

Atualmente as grandes organizações estão enxergando que o mercado percebe a constituição do valor social quando demonstram alguma preocupação com as comunidades em que estão localizadas, com destaque para a valorização da diversidade, gerando ganhos financeiros e espaço de mercado (BARBIEIRE e SIMANTOB, 2007).

Então, as empresas que não adotam a prática da integração e inclusão acaba perdendo mercado para o concorrente que se envolve nessas questões sociais.

\section{Metodologia}

Metodologia científica é o estudo sistemático e lógico dos métodos empregados nas ciências, seus fundamentos, sua validade e sua relação com as teorias científicas (TARTUCE, 2006).

Dessa forma, no presente estudo, foi realizada uma pesquisa qualitativa de caráter exploratório quanto à abordagem e bibliográfica quanto aos procedimentos, buscando qualificar o problema da inclusão de pessoas com deficiência no mercado de trabalho.

A pesquisa qualitativa não se preocupa com representação numérica, mas, sim, entender os diversos fenômenos humanos, com o aprofundamento da compreensão de um grupo social ou de uma organização por exemplo.

Adequando ao conhecimento "[...] os métodos qualitativos buscam explicar o porquê das coisas, exprimindo o que convém [...], mas não se submetem à prova de fatos, 
pois os dados analisados não são métricos e se valem de diferentes abordagens" (GOLDENBERG, 1997, p. 49).

A pesquisa bibliográfica é feita a partir do levantamento de referências teóricas já analisadas, e publicadas por meios escritos e eletrônicos, mostrando que as opiniões que constam neste artigo são sustentadas através de pesquisas feitas em livros, artigos científicos já publicados e páginas da internet (FONSECA, 2002).

Para Gil (2007), os exemplos mais característicos desse tipo de pesquisa são sobre investigações sobre ideologias ou aquelas que se propõem à análise das diversas posições acerca de um problema.

Então, a presente pesquisa desenvolveu-se por um processo constituído de várias fases, desde a revisão de literatura até a apresentação e discussão dos resultados e teve como objetivo proporcionar respostas ao objetivo proposto (GIL, 2007).

\section{Resultados e Discussão}

Os métodos de análise do conteúdo, utilizado para a categorização das informações coletados, se configura em um apanhado de técnicas que possibilita, por meio de procedimentos sistemáticos de descrição do conteúdo, a realização de conclusões acerca da produção e recepção de determinada informação (BARDIN, 1988).

O presente estudo buscou conhecer os desafios e superações no ambiente de trabalho da pessoa com deficiência, e sobre os direitos para sua inserção no mercado.

Observou-se ainda um expressivo preconceito sobre a $\mathrm{PcD}$, que para as empresas, as PcD não têm capacidade de realizar um trabalho como qualquer outra pessoa, e mesmo com os sistemas de cotas algumas empresas não cumpre o que determina a Lei, porém as empresas com grandes números de funcionários estão sendo obrigadas a fazer a contratação para não sofrerem penas administrativas.

Por fim, entendeu-se que a pesquisa trouxe uma nova visão da luta que tem a pessoa com deficiência para estar inserida no mercado de trabalho, sendo que para que estas sejam inseridas, elas passaram por vários desafios como, a superação 
das barreiras ao enfrentar as grandes empresas capitalistas e a falta de respeito da sociedade.

\section{Conclusão}

$\mathrm{Na}$ presente pesquisa, observou-se que os direitos legais indicam para a necessidade e a importância de as pessoas com deficiência serem incluídas tanto nos contextos educacionais e sociais quanto trabalhistas.

$\mathrm{Na}$ maioria das vezes a classe empresarial contrata as pessoas com deficiência para cumprir a lei, sem ter critérios claros e definidos ou até mesmo uma estrutura em termos de recursos estruturais e humanos que possam garantir 0 acompanhamento e a produtividade dessas pessoas para que elas desenvolvam suas habilidades.

Muitas são as medidas que devem ser tomadas em razão a uma inclusão efetiva. Deve-se estabelecer uma relação de parceria e cooperação entre empresas, sociedade e governo. A função do governo seria fornecer dados sobre a deficiência, as capacidades dessas pessoas, sobre como modificar o ambiente de trabalho, além de implementar políticas educacionais inclusivas e políticas urbanas que favoreçam a acessibilidade.

Como contribuição das empresas, espera-se adaptações da organização, dos ambientes de trabalho e dos processos, para que a pessoa com deficiência possa ser incluída de forma efetiva, respeitosa e segura. Esta relação entre governos, empresas e sociedade ainda não está adequada de forma a favorecer a inclusão no trabalho.

O presente trabalho não possui considerações conclusivas em razão de o assunto ser complexo e de muitas análises e discussões em torno dos fatos.

Considera-se que essa pesquisa permitiu aumentar o conhecimento, a compreensão acadêmica e profissional sobre o tema, promovendo reflexões e despertando para o problema, no propósito de ajudar na conscientização da sociedade como um todo a fim de proporcionar:

a) primeiro a capacitação da $\operatorname{PcD}$ que não tem, muitas das vezes, condições para expressar suas necessidades e indignações e, 
b) segundo, promover maior um esclarecimento aos empresários sobre a importância de permitir trabalho também à essas pessoas, sem a obrigatoriedade de uma lei, mas pelo simples fato de esta população ter capacidade de contribuir para o crescimento de qualquer organização, podendo trazer resultados extremamente positivos para o negócio.

Recomenda-se que novas pesquisas sejam realizadas e exploradas em relação ao tema da Pessoa com Deficiência no mercado de trabalho, para que novos resultados sejam alcançados, e confrontados com os revelados por este trabalho.

\section{Referências}

BARBIERI, J. C.; SIAMANTOB, M. A. Organizações Inovadoras Sustentáveis: Uma reflexão sobre o futuro das organizações, São Paulo, SP: Atlas, 2007.

BECHOT, P. B; WEISS, S.L.I. A inclusão das pessoas com necessidades educacionais especiais no mercado de trabalho. Monografia apresentada ao curso de especialização em psicopedagogia do Instituto Catarinense de PósGraduação. 2005. Disponível em:<http://www.inovarse.org/sites/default/files/T_15_289_2.pdf> Acesso em: 07 set. 2019.

BOHLANDER, George. Administração de Recursos Humanos.14. ed. São Paulo: Ed. Cengage Learning, 2009.

DUTRA, J. S. Gestão de Pessoas. São Paulo: Atlas, 2011.

DAFT, R. L. Administração. São Paulo: Pioneira Thomson Learning, 2005.

FONSECA, J. J. S. Metodologia da pesquisa científica. Fortaleza: UEC, 2002. Fundação DorinaNowill. Lei de Cotas: ações e desafios para a empregabilidade de pessoas cegas. Disponível em: <https://www.fundacaodorina.org.br/blog/lei-decotas/> Acesso em: 08 set. 2019.

GIL, A. C. Métodos e técnicas de pesquisa social. 5. ed. São Paulo: Atlas, 1999. Disponível em: <http://www.ufrgs.br/cursopgdr/downloadsSerie/derad005.pdf> Acesso em: 20 out. 2019.

GOLDENBERG, M. A arte de pesquisar. Rio de Janeiro: Record, 1997. Disponível em: <http://www.ufjf.br/labesc/files/2012/03/A-Arte-de-Pesquisar-Mirian-

Goldenberg.pdf> Acesso em: 20 out. 2019.

IBGE. Pessoas com deficiência no Brasil. Disponível em:

<https://censo2010.ibge.gov.br/resultados.html> Acesso em: 17 ago. 2019. 
Instituto Ethos de Empresas e Responsabilidade Social - ETHOS. Indicadores Ethos de Responsabilidade Social Empresarial. São Paulo: Instituto Ethos, 2007. Disponível em <http://www1.ethos.org.br/EthosWeb/arquivo/0-A 34a2011_IndicadoresEthos-Sebrae_PORT.pdf> Acesso em: 08. Set. 2019.

Instituto Ethos de Empresas e Responsabilidade Social - ETHOS. O que as empresas podem fazer pela inclusão das pessoas com deficiência. São Paulo: Instituto Ethos, 2002. Disponível em: <

http://bippsp.bipp.pt/documentos/integracao/Documentos/O\%20que\%20as\%20Empr esas\%20podem\%20fazer\%20pela\%20Inclus\%C3\%A30\%20das\%20Pessoas\%20co m\%20Defici\%C3\%AAncia.pdf >. Acesso em: 08 set. 2019.

LANCILOTTI. A integração pelo trabalho numa sociedade de exclusão. Encontro Anual da Associação Brasileira de Pós-Graduação e Pesquisa em Educação.

Caxambú. ANPED, 2001.

MAZZOTTA, Marcos José Silveira. Educação especial no Brasil: história e políticas públicas. 5. ed. São Paulo: Cortez, 2005.

MINISTÉRIO DO TRABALHO E EMPREGO (MTE). Características do emprego formal segundo a Relação Anual de Informações Sociais - 2017. Brasília: MTE, 2018.

PASTORE, J. Oportunidades de trabalho para portadores de deficiência. São Paulo: LTr, 2000.

PESQUISA NACIONAL POR AMOSTRA DE DOMICÍLIOS CONTÍNUA.

Distribuição de pessoas desocupadas - $2^{\circ}$ trimestre de 2019. Disponível em: <https://www.ibge.gov.br/estatisticas/sociais/trabalho/9173-pesquisa-nacional-poramostra-de-domicilios-continuatrimestral.html?edicao $=25199 \& \mathrm{t}=$ destaques $>$ Acesso em:17 ago. 2019.

Portal do Ministério do Trabalho e Emprego, Razões da criação da lei de cotas. Disponível em: <http://trabalho.gov.br/fisca_trab/razoes-da-criacao-da-leidecotas.htm>. Acesso em: 07 set. 2019.

RIBEIRO, M.A.; CARNEIRO, R. A inclusão indesejada: as empresas brasileiras face à lei de cotas para pessoas com deficiência no mercado de trabalho. Organizações \& Sociedade, Salvador. 2009.

SCHWARZ, A.; HABER, J. Cotas: como vencer os desafios da contratação de pessoas com deficiência. São Paulo: I. Social, 2009.

STAINBACK, Susan; STAIMBACK, W. Inclusão: um guia para educadores. Porto Alegre: Artmed, 1999.

SALOMAO, P. E. A. et al. As Tecnologias de Informação e Comunicação (TIC) no ensino superior. Revista Multidisciplinar do Nordeste Mineiro, v. 1, 2018.

TARTUCE, T. J. A. Métodos de pesquisa.Fortaleza-CE: UNICE, 2006. 
Revista Multidisciplinar do Nordeste Mineiro, v1. 2020/01 ISSN 2178-6925

WILLIAMS, J.W. Habilidades no local de trabalho mudando mentes. Fator De Diversidade, Jan. 2000. 